sylvania Shipbuilding Co. propelled by geared steam turbines and having electrical auxiliaries.

At the present time there are a number of oil-enginedriven cargo vessels with electric auxiliaries and others with electric drive and electric auxiliaries being projected in this country, and it is believed from this time the field will rapidly broaden until a great many of the merchant vessels will be so propelled and operated.

Extensive progress has been made recently in the merchant field in the use of the electric drive, the first installation on record in this country being two fire boats constructed in 1908 on the Great Lakes. Since

\section{ANNUAL REPORT OF THE LIGHTING AND ILLUMINATION COMMITTEE}

To the Board of Directors,

IEG to submit on behalf of the Lighting and Illumination Committee the following report for the year 1919-20.

\section{ACTIVITIES OF THE COMmitTeE}

Your Lighting and Illumination Committee, at its meeting on October 10th., 1919, decided to conduct a symposium on "Distribution Systems for Street

ELECTRIO PROPULSION OF SHIPS (Not Including Naval)

\begin{tabular}{|c|c|c|c|c|c|c|c|c|c|c|c|}
\hline Date & Name of ship & Type of ship & $\begin{array}{l}\text { Type of } \\
\text { propulsion }\end{array}$ & $\begin{array}{c}\text { Size } \\
\text { in } \\
\text { tons }\end{array}$ & S H P & $\begin{array}{c}\text { Pro- } \\
\text { peller } \\
\text { R P M }\end{array}$ & $\begin{array}{l}\text { A C. } \\
\text { or } \\
\text { D C. }\end{array}$ & Voltage & $\begin{array}{l}\text { Gen. } \\
\text { units }\end{array}$ & $\begin{array}{l}\text { Motor } \\
\text { units }\end{array}$ & Remarks \\
\hline 1910 & Jos. Medill & Fireboat & Steam electric & $\ldots$ & 500 & 190 & D C & 250 & 2 & 2 & Twin screw \\
\hline 1910 & Graeme Stewart & Fireboat & Steam electric & $\ldots$ & 500 & 190 & D C & 250 & 2 & 2 & Twin screw \\
\hline 1913 & Tynemouth & Cargo & Diesel electric & 3400 & 500 & 78 & A C & 500 & 2 & 1 & $\begin{array}{l}\text { Method abandoned as Die- } \\
\text { sel engine misfit }\end{array}$ \\
\hline 1916 & Mjolner & Cargo & Steam electric & 800 & 850 & 90 & A C & 440 & 2 & 2 & Geared single screw \\
\hline 1918 & Wulsty Castle & Cargo & Steam electric & 6400 & 1500 & 76 & A C & 650 & 2 & 2 & Geared single screw \\
\hline 1918 & Panoil & Tanker & Steam electric & 1400 & 620 & $150-180$ & A C & 440 & 1 & 2 & Twin screw \\
\hline 1918 & Mexoil & Tanker & Steam electric & 1400 & 620 & $150-180$ & A C & 440 & 1 & 2 & Twin screw \\
\hline 1918 & Fuel Oil & Tanker & Steam electric & 1400 & 620 & $150-180$ & A C & 440 & 1 & 2 & $\begin{array}{l}\text { Twin screw } \\
2-125 V^{\prime} \text { gen. }\end{array}$ \\
\hline 1919 & Mariner & Trawler & Diesel electric & 500 & 400 & 200 & D C & 250 & 2 & 1 & Single screw $1-250 \mathrm{~V}$.motor \\
\hline 1920 & Crudoil & Tanker & Steam electric & 1400 & 620 & $150-180$ & A C & 440 & 1 & 2 & Twin screw \\
\hline 1920 & Elfay & Schooner yacht & Diesel electric & 313 & 90 & 360 & D C & 125 & 1 & 1 & Single screw \\
\hline Building & Guinivere & Yacht & Diesel electric & 642 & 550 & 220 & D C & 250 & 2 & 1 & Siligle screw \\
\hline $\begin{array}{l}\text { Building } \\
\text { Building }\end{array}$ & $\begin{array}{l}4 \text { ships } \\
\text { United States }\end{array}$ & cutters & Turbo electric & 1600 & 2600 & 120 & A C & 1150 & 1 & 1 & Synchronous motor \\
\hline & $\begin{array}{l}\text { Shipping } \mathrm{Bd} . \\
12 \text { ships }\end{array}$ & Cargo & Turbo electric & 9600 & 3000 & 100 & A C & 2300 & 1 & 1 & Induction motor \\
\hline Bullaing & $\underset{\text { Company }}{\text { Cnited }}$ & Cargo \& Pass. & Turbo electric & 6550 & 3000 & 100 & $\mathbf{A} \mathbf{C}$ & 1150 & 1 & 1 & Synchronous Motor \\
\hline
\end{tabular}

these first installations in $19088^{\circ}$ a total of 28 electrically propelled vessels have been constructed or projected, all but three of these being built or building in this country. Among these may be mentioned the four tankers constructed by the Pan American Petroleum Transport Co., the trawler Mariner equipped at the New London Ship and Engine Bldg. Co.'s works, the passenger ship $C u b a$, the 12 ships projected by the Shipping Board, and the cargo vessel Wulsty Castle constructed in England. This growing use of electric drive within the last two or three years would indicate a still further and more rapid adoption.

While the above gives a preliminary and general outline of the history and development of electricity on shipboard, a more complete and detailed historical review of this subject will be compiled during the coming year for submission to, and publication by, the Institute.

H. L. HIBBARD
Lighting" at one of the Institute meetings of the year, and to schedule, if possible, a paper on "An Analysis of Daylight Saving" at the Midwinter Convention. These plans resulted in holding the national meeting in Chicago on January 9th and 10th under the auspices of this Committee, at which three papers were read dealing with street lighting distribution systems. One of these papers on series systems was presented by W. P. Hurley, another, on multiple systems, by Ward Harrison, and a third, on constant potential series systems, by Charles P. Steinmetz.

The Chicago meeting was very successful and the discussions at both sessions were as complete as time permitted. At the afternoon session, prepared discussion was presented by C. H. Shepard of the Lincoln Park Board, Chicago; by N. B. Hinson, of the Southern California Edison Co.; by F. F. Fowle and W. F. Parker. In the evening, following Dr. Steinmetz's paper, illustrated discussion was presented by 
F. A. Vaughn together with a description of the new group lighting system now used in Chicago for underground distribution for residence street lighting, by Deputy Commissioner Nixon. The newest things brought out in this discussion were the Chicago group lighting system and the conduit return system used in Southern California.

At the Midwinter convention in New York in February 1920, a paper on "Daylight Saving" was presented by Preston S. Millar under the auspices of the Lighting and Illumination Committee. This paper contained a comprehensive analysis of the subject and the general purpose kept in view by the author in the preparation of the paper is indicated by the following quotation from the opening paragraph of his remarks:

In accepting the invitation of the Lighting and Illumination Committee to present a paper on "Daylight Saving," the author stipulated that in order to consider the subject comprehensively, a considerable part of the paper would have to be devoted to matters remote from electrical engineering. The economic and sociological aspects of daylight saving surpass in importance the effect upon use of artificial light. Any treatment which should ignore these important features would lack perspective and would be likely still further to increase confusion on a subject which is greatly in need of clarification. Accordingly this paper includes a brief survey of daylight saving in its several aspects.

Your Lighting and Illumination Committee decided this year, as last year, to send a circular letter to the Chairmen of all of the Institute Sections, suggesting that one meeting of the year in each Section might profitably be devoted to an illumination topic. The following quotations from this year's letter will indicate the point of view taken by the Committee:

At the last meeting of the Lighting and Illumination Committee of the American Institute of Electrical Engineers held on October 10, 1919, in Philadelphia, it was decided to suggest to the Chairmen of the various Institute Sections that it might be desirable to include on the program for the current year one meeting devoted to some illumination topic.

Where the Local Section of the Institute is in a territory having a Local Section of the Illuminating Engineering Society it would be desirable in connection with the meeting devoted to illumination to have said meeting as a joint session between the two organizations.

The responses to this letter were widespread and a number of excellent papers dealing with various aspects of lighting and illumination were presented before some of the Local Sections during the course of the year.

\section{Developments in the Lighting Field}

Under date of January 16, 1920, the Chairman of the Board's Committee on Technical Activities sent a letter to the Chairmen of the Technical Committees, which contained, among other items, the following:

It was brought out very strongly at the last annual convention in the discussion of the Development Committee's report that the reports of Technical Committees should cover the activity in the particular line covered, so that anyone reading these reports from year to year would obtain a review of the progress of the art.

These reports should cover notable installations or developments during the year and it is suggested in view of the fact that in the past little has been done in this respect, that the reports might be a review of the state of the art up to date. One plan that was suggested which seemed to have considerable merit, was that the Chairman of the Committee might apportion to different members of the Committee certain parts of the field covered by the Committee's activities, and these should be edited and combined to be the report of the Committee.

Acting on this suggestion, the Chairman of your Lighting and Illumination Committee has addressed the members of the Committee in an effort to gather the important developments in the lighting field. These have been edited and combined so as to be the main portion of this report. It should be stated in advance, however, that the developments in the field of street lighting distribution, which were covered in the papers read before the Chicago meeting in January, will not be discussed in this report, since they will be found completely treated in the TRANSACTIONS of the Institute. The same statement applies to the important question of "Daylight Saving" which was covered in the paper before the Midwinter convention, and which will therefore be found in due time in the Institute Transactions.

\section{General Notes}

As one of the results of the war, in its effects on the lighting field, a number of interesting papers have been presented during the past year. The titles of several of these papers will indicate the rather unusual character of the material which has been gathered under war conditions. Among these may be mentioned the following: "The Science of Marine Camouflage Design," "Painting Battleships for Low Visibility," "Camouflage," "The Principles of Camouflage" and "Industrial Lighting and its Relation to the War."

Following the war, the past year has witnessed an unusual increase in the interest taken in lighting in general. It has been felt that the past twelve months have, in fact, marked an awakening among the users of artificial light to its possibilities. This has been evidenced by the efforts made by various societies, organizations and associations, to have placed before them the facts as to what light can do in the way of increasing production, decreasing accidents and of improving the morale of employees in industrial plants. It would appear that a transition period is in progress in the lighting field, if one can judge by the trend of the developments during the year. Among these developments the following may be mentioned:

1. A widespread recognition of good lighting as an important aid to manufacturing.

2. The increasing use of the foot-candle meter as a means of checking illumination intensity in various parts of a lighted room.

3. Progress of industrial lighting codes.

4. Progress in automobile lighting regulations in several states.

5. Development of the bowl enameled Mazda C lamp to give better diffusion. The latest lamps of 
this type have a feathered edge of the enameling to prevent a sharp "cut off" line.

6. The proposal of a plug outlet for permitting the convenient change of ceiling and wall fixtures.

7. The increasing tendency on the part of fixture manufacturers to make and advertise ready-to-hang types of fixtures. These fixtures are principally for commercial and industrial lighting but there is also some tendency to invade the residence lighting field, which seems to be an improvement both from the scientific and the commercial standpoints.

8. The formation of the fixture manufacturers association, with an attempt (as mentioned in item 6 above) to perfect a method of fixture hanging which will permit electric light fixtures to be hung as easily as a picture and moved, by the renter, as easily as a portable lamp can be moved, thus encouraging the renter to install improved fixtures as a substitute for bad designs often found to be in use when a house or an apartment is rented.

9. Progress in the enforcement of the industrial and automobile headlight codes. New York, Connecticut, California, Wisconsin and Pennsylvania have adopted the I. E. S. S. A. E. automobile headlight specifications, and it is reported that in all of these states, except New York, there are practical attempts at enforcement, which are gradually producing results that are favorable.

10. An important development in street lighting units is the "Duoflux" standard. This unit contains two lamps (in one type, one 1000 candle-power and one 250 candle-power) and by means of a relay located in the casing of the fixture, the 1000 candle-power lamp will be extinguished at midnight, and the 250 candlepower lamp lighted.

\section{DEVELOPMENTS IN LIGHTING UNITS}

The RLM standard dome reflectors have during the year become more widely adopted and nearly all the leading steel reflector manufacturers recommend these standards for industrial lighting.

Among the new fixtures and auxiliaries developed during the year, there may be mentioned the enclosing type of interior units which consist of a combination reflector, a diffuser and an enclosing globe in one piece. Another interesting development has been that of simplified units of the semi-indirect type, and the increased application of the incandescent lamp for moving picture projection. In street lighting, the single unit of high candle-power has quite largely replaced the cluster form of post, the former being considered superior both from the standpoint of efficiency as well as of appearance.

Luminous arc lamp efficiencies have been increased by the compounding under high pressure of the ingredients of the electrodes. It is reported that by this means, 30 to 40 per cent more light is produced than with the previous standard electrodes, with at least equal life. For the same light as formerly, increased life of the electrodes is expected.

\section{IMPORTANT LIGHTING INSTALLATIONS}

The unusual lighting effects secured at the Chicago and the Buffalo electrical shows in 1919 may be mentioned. At Chicago, the so called "Palace of Aladdin" was housed in a structure 50 feet high, and interesting lighting effects secured with glass jewels, painted mirrored glass and flood lights. At Buffalo, 5000 white Mazda lamps were employed along with nearly 5000 illuminated disks distributed among the roof girders. The application of spectacular lighting of this general nature, was seen at its best, perhaps, in the "Jewel Portal for the Victorious Army" in New York and the "Altar of Victory" in Chicago. The use of 30,000 so called jewels in each of these remarkable lighting displays, contributed largely to the spectacular effects secured.

The effect of the war on industrial lighting has been to stimulate the interest taken in better factory lighting the past year. The tendency to employ illuminating engineers for the handling of industrial lighting schemes, rather than to entrust this work to the electrical department as heretofore, has been noticed. In one large industry a research is being conducted to ascertain the effects of lighting on production. The large increase in wages in the industries, with very little increase in the cost of factory lighting, has reduced the cost of good lighting in term of wage equivalents. This same fact has also made lighting the more important in terms of its effects on increased production and reduced spoilage.

A notable example of modern factory lighting installations is contained in a booklet recently issued by one of the lamp manufacturers. It would have been very difficult a short time ago to have published a book of this kind without relying upon the artist to touch out undesirable features and to paint in desirable ones. This entire booklet contains unretouched photographs of industrial lighting installations and is a commentary upon the improvements which have been made in this part of the illumination field.

In street lighting a number of important installations have been made. Among these may be mentioned the main street lighting in Salt Lake City consisting of 70 standards, each equipped with three 6.6ampere ornamental luminous arc lamps. These units are spaced about 100 feet and the overall height is 29 feet. Although this particular system was put into operation prior to the current year, it represents an example of intensive street lighting which is coming more and more into prominence. More recent systems of intensive street lighting are the Triangle Lighting in San Francisco, first put into operation in January 1919, and the Broadway system in Los Angeles, put into operation in January 1920. The latter installation consists of 134 two-light ornamental 
luminous arc standards 106 feet apart and 27 feet high . The installation cost was about $\$ 6.50$ per front foot of property, and the annual operating cost is about $\$ 1.00$ per front foot.

The Broadway system at Saratoga Springs is of interest in that about a mile of street is to be lighted by 69 of the new "Duoflux" units mentioned above. Each of these units contains two lamps, one of 1000 candle-power and one of 250 candle-power. This installation, which is to be put into operation about June 1920 , will cost about $\$ 32,000$ for its installation and for operation, about $\$ 10,350$ per annum.

\section{Contributions to THE ART}

Important papers contributed during the year include a discussion entitled "Coefficients of Utilization" by Ward Harrison and Earl A. Anderson, published in the March 20, 1920 issue of the Transactions of the Illuminating Engineering Society. This paper presents a method for the direct determination of coefficients of utilization applying to installations of all ordinary types of lighting units in rooms of varied proportions and different ceiling and wall colors. Actual colors for ceiling and wall surfaces covering 32 different shades with the corresponding reflection factors are included in the printed paper.

A paper on "Opportunities of Extending Lighting through New Applications" was read by R. M. Searle before the annual convention of the Illuminating Engineering Society in October 1919, which contains references to the following divisions of the lighting field: Street Lighting, Display Lighting, Flood Lighting, Lighting of Freight Terminals, Industrial Lighting, Stairway Lighting and Lighting for Community Affairs, this list giving an idea of some of the fields in which developments may be expected.

The following quotation from an address of President S. E. Doane before the Thirteenth annual convention of the Illuminating Engineering Society is of interest:

The war has taught us that we have been regarding electric lighting, to use a phrase that one of my associates has given me, as a janitor service, whereas we should have looked at lighting as an item in the cost of production or in the cost of sales, and regarded it as any other factor in the cost. Then we would have examined, as have men within the last year or two, under what light we could get the maximum of visual acuity or speed of visual reaction. During the war time we have had some demonstrations. Mr. Durgin has given the most and the best of the practical demonstrations of how to apply this knowledge that visual acuity increases with the intensity of light and the speed of reaction increases production.

Its application to production has been spectacular, and the results have been remarkable. As a matter of interest and as a measure of our opportunities I would like to use some figures from the lamp industry. Sixty-five per cent of the output of the lamp manufacturers, according to our estimates, is used in that portion of our business which would be affected by this knowledge. In other words, more than half of the electrio lighting of this country can be affected and will be affected by the better knowledge we have of the production or increase in visual acuity and speed of visual reaction under intensive lighting.
For those who may be especially interested in the progress of the lighting and illumination art, attention is directed to the annual report of the Committee on Progress published each year by the Illuminating Engineering Society. The last report of this kind, covering 80 pages, will be found in the Transactions of the Illuminating Engineering Society for November 20, 1919.

C. E. Clewell, Chairman.

\section{ANNUAL REPORT OF THE POWER STATION COMMITTEE}

To the Board of Directors,

$\mathrm{D}$ URING the year 1919-1920 the Committee held two meetings, mainly devoted to discussion of papers presented, in person by the writers for comments and suggestions. The contributions to the activities of the Institute under the auspices of this Committee were as follows:

A symposium on steam turbine design, with the following papers:

Present Limits of Speed and Power of SingleShaft Curtis Steam Turbines, by Eskil Berg.

Present Limits of Speed and Power of SingleShaft Steam Turbines, by J. F. Johnson.

Present Limits of Speed and Output of Single-

Shaft Turbo Generators, by F. D. Newbury.

A plea for standardization in statistical records of state and governmental bodies reporting efficiencies of power plants, with the presentation of the following paper:

Essential Statistics for General Comparison of Steam Power Plant Performance, by W. S. Gorsuch.

A symposium on excitation, with the papers to be presented at the Annual Convention as follows:

Considerations which Determine the Selection and General Design of an Exciter System, by J. T. Barron and A. E. Bauhan.

Factors in Excitation Systems of Large Central Station Steam Plants, by A. A. Meyer and J. W. Parker.

Exciters and Systems of Excitation, by H. R. Summerhayes.

Application of D. C. Generators to Exciter Service, by C. A. Boddie and F. L. Moon

Exciter Practise in the Northwest, by J. D. Ross.

Generator Excitation Practise in the Hydro-Electric Plants of the Southern California Edison Company, by H. H. Cox and H. Michener.

The committee also considered the question of making suggestions for the activities of the incoming committee for the ensuing year, and recommended for consideration the following: 